\title{
Buruli Ulcer: A Case Report
}

\section{Buruli Ülseri: Olgu Sunumu}

Raimundo Geronimo da Silva

Junior $^{1}$

Vitoria Castelo Branco Rocha

Ibiapina do Monte ${ }^{2}$

Thiago Assis Borges Morais ${ }^{3}$

${ }^{1}$ Surgical Pathologist of Lapac Laboratory, Brazil

${ }^{2}$ Medical Student at the Federal University of Piauí, Brazil

${ }^{3}$ Medical Student at the State University of Piauí, Brazil

Öz

Buruli ülseri, Mycobacterium ulcerans'ın neden olduğu, 30'dan fazla ülkede tespit edilen, lepra ve tüberkülozdan sonra bir mikobakteriozis türü olarak üçüncü sırada ortaya çıkan enfeksiyöz bir hastalıktır. Bu makalede nadir görülen bir bruli ülseri olgusunu; hastalığın erken tanısı ile estetik ve fonksiyonel sekellerin önlenmesi için yararlı morfolojik bulguları ve tamamlayıcı tekniklerini vurgulayarak sunduk.

Anahtar Kelimeler: Mycobacterium ulcerans, Buruli ülseri, teşhis

\section{Abstract}

Buruli ulcer is an infectious disease caused by Mycobacterium ulcerans and considered the third mycobacteriosis in occurrence after leprosy and tuberculosis, having been detected in more than 30 countries. We report a case of this rare disease, highlighting the morphological findings and complementary techniques useful for early diagnosis and consequent prevention of aesthetic and functional sequels.

Keywords: Mycobacterium ulcerans, Buruli ulcer, diagnosis

\section{INTRODUCTION}

Buruli ulcer (BU), also known as Bairnsdale ulcer or Daintree ulcer is a destructive infection of skin and soft tissue caused by Mycobacterium ulcerans ( $M$. ulcerans). It is the third mycobacteriosis in occurrence after leprosy and tuberculosis. BU has been reported in 30 countries in Africa, The Americas, Asia and the Western Pacific, mainly in tropical and subtropical regions. The $M$. ulcerans is an acid-alcohol resistant bacillus (BARR) predominantly extracellular and current data suggest that this Mycobacterium does not exist freely in the environment, as previously thought. It probably occupies a specific niche within aquatic environments (for instance, small aquatic animals), from where it is transmitted to humans by an unknown mechanism $(1,2)$. The first Brazilian case was registered in 2007 and described a 65 years old patient with two years of ulcerated lesion evolution and osteomyelitis association. In 2009, McGann et al. published the second case in an English patient who contracted the disease after visiting the Pantanal region, in the center-west of Brazil (3).

The M. ulcerans possesses a giant virulent plasmid, composed of 174-kbp nucleotides, coding polyketide synthase to produce macrolide toxin called mycolactone that causes extensive, chronic, and necrotizing damage to the papillary dermis, subcutaneous fat, and muscles (fascia and bones are sometimes affected), resulting in deformity and disability (4).

These lesions are often delayed in non-endemic regions and in the most prevalent areas and are often confused with other infectious diseases such as leishmaniasis, syphilis, mycoses, and malignant neoplasms such as squamous cell carcinoma (1). Our objective is to report a case of this rare infection, highlighting the importance of early diagnosis and treatment to minimize morbidity, costs and prevent long-term disability.

\section{CASE}

A 47 years old, male patient, native of the northern region of Brazil, who presented an ulcerated arm lesion with progressive growth and not respond to antimicrobial therapy one year ago. He had a previous biopsy with inconclusive diagnosis. The patient was

Address correspondence to: Raimundo Geronimo, Silva Junior Lapac Laboratory, Anísio de Abreu 502 South, Teresina - Brazil 


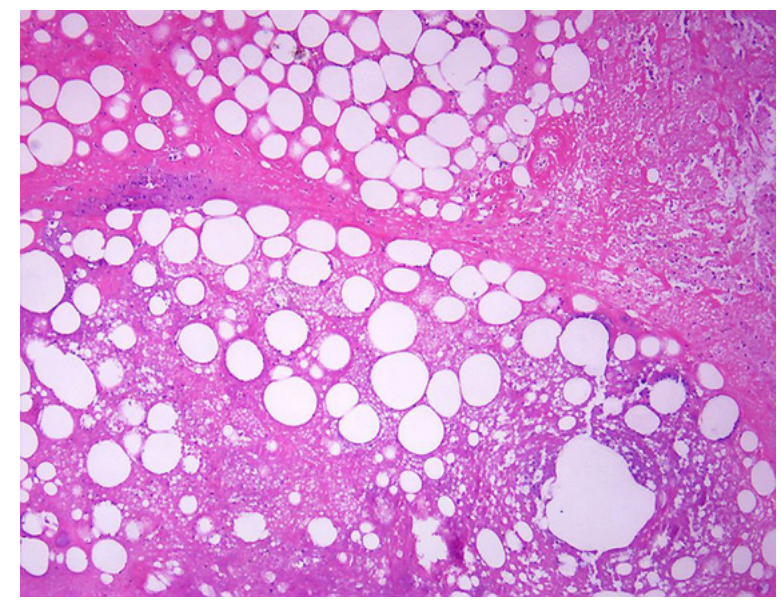

Figure 1. H\&E, X20; Histopathologically, marked coagulation necrosis involving the dermis and subcutaneous tissue

then subjected to a new biopsy. In this biopsy, Skin with epidermal ulceration, marked coagulation necrosis involving the dermis and subcutaneous tissue and discrete mixed inflammatory infiltrate, as well focus of vasculitis was histopatologically determined (Figure $1,2)$. The presence of granulomas was not detected. The search for BAAR using Fite-Faraco stain revealed numerous bacilli in globes (Figure 3 ).

\section{DISCUSSION}

$\mathrm{BU}$ is a relatively recent disease, especially in Brazil. The first case that was described in detail in the world occurred in 1948, while the first Brazilian case was registered in 2007 . The lack of knowledge

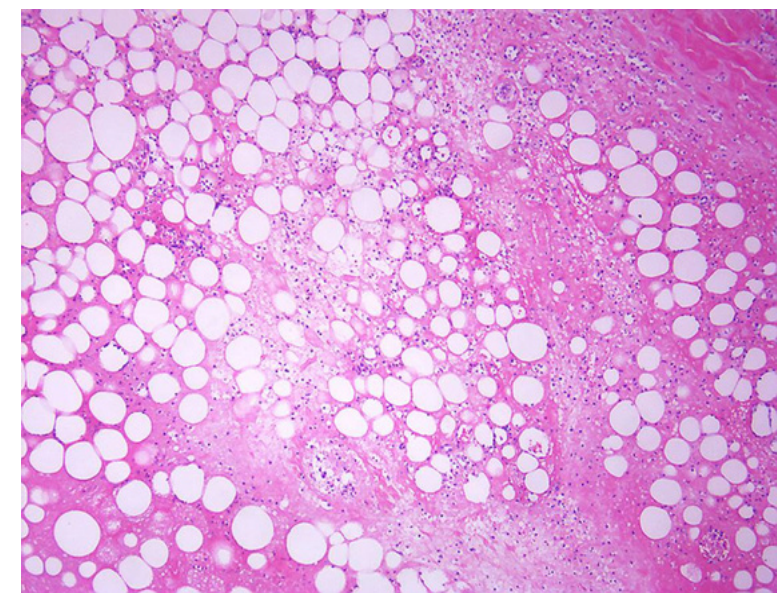

Figure 2. H\&E, X20; Histopathologically, marked coagulation necrosis involving the dermis and subcutaneous tissue

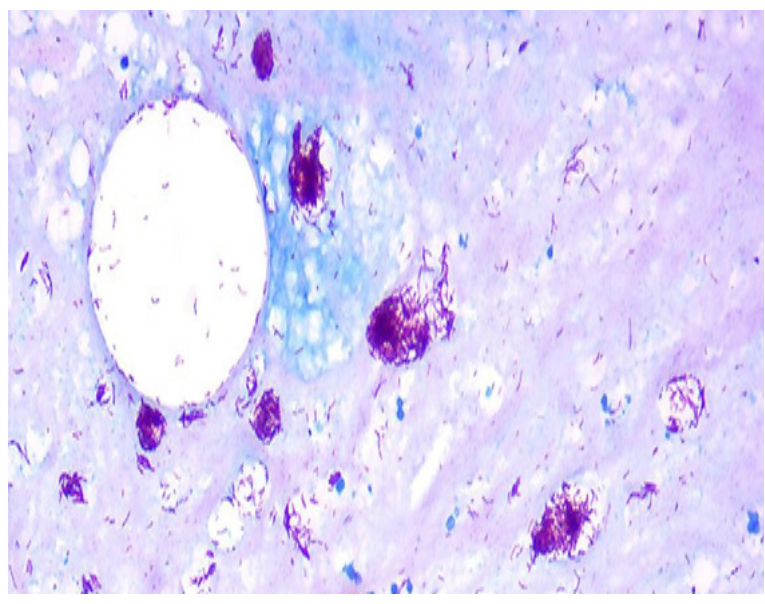

Figure 3. Fite-Faraco stain, X40; Numerous bacilli in globes

about this disease by health professionals interferes with the notification and, therefore, difficult the epidemiological monitoring. Although BU can affect patients of all ages, the majority of these patients are children younger than 15 years, with a peak age of onset between 10 and 14 years $(1,5)$.

After a primary infection, the disease can evolve through spontaneous cure, with clinical manifestations or it become a latent infection and may be activated later. After an incubation time, during 2 or 3 months, the infection begins appearing like an erythema whose evolution is a nodule formation, papule or a plaque on the skin that advance throw dermis and by subcutaneous tissue may reach the fascia. This is the pre-ulcerative stage, which is followed by the ulcerative stage with an ulcer of poorly delimited borders, which may remain small or progressively increase in size (1).

The diagnosis is clinical and laboratorial, being the tests most frequently used for the diagnosis: Direct search for acid-fast bacilli, culture in vitro, Polymerase Chain Reaction (PCR) with the IS2404 target sequence and histopathological exam. The positivity rate of different tests depends on the quality of the samples, and may vary according to the type of sample and clinical form of the disease. For microscopy and culture, positivity rates ranging from $30 \%$ to $60 \%$ have been reported. Among true BU cases (that is, those confirmed by at least two positive laboratory tests), direct smear examination and culture are less frequently positive when the nodules are tested ( $60 \%$ of positivity) than when samples are 
collected from edematous forms ( $80 \%$ of positivity). M. ulcerans is particularly difficult to culture from bone ( $20 \%$ of positivity). Studies conducted in different African countries report PCR positivity rates from $70 \%$ to higher than $90 \%$, and sensitivity ranging from $85 \%$ to $89 \%$ (4). The sensitivity of histopathology is about $90 \%$. To avoid a misdiagnosis caused by falsepositive or false-negative results, it is recommended that two tests have positive results before a definitive diagnosis is made (6).

There are four histopathological evolutionary stages of BU: Non-ulcerated lesions, ulcerative lesions, organizing (early granulomatous) stage and healing stage. In the non-ulcerated necrotic stage, the epidermis is hyperplastic and in the upper dermis, collagen degeneration, edema and discrete inflammatory infiltrate can be observed. At this stage vasculitis and coagulation necrosis involving the dermis and subcutaneous tissue can be detected. In these areas of necrosis the BAAR are numerous and arranged in globes. On the ulcerated necrotic stage, there is hyperplasia of the epidermis adjacent to ulcer and similar to that which occurs in the non-ulcerative phase, coagulation necrosis normally reaches even subcutaneous tissue and fascia. Vasculitis and calcification foci can be found. Finally, the cicatricial stage is characterized by severe dermal fibrosis and no detectable bacilli $(1,5)$.

The present case is a patient from the northern region of Brazil where previous cases have already been diagnosed and who sought medical attention because of ulcerative phase lesion not response to treatment for bacterial infections of the skin and soft tissues. Microscopically, marked necrosis of the deep dermis and subcutaneous tissue was observed, in contrast to a discrete non-granulomatous inflammatory infiltrate (Figure 1 and 2). These morphological findings are considered as the clues to the correct diagnosis. In this case was performed Fite-Faraco stain, which revealed numerous BAAR in the areas of necrosis and adjacency (Figure 3), allowed the correct diagnosis. The patient immediately started the treatment with marked regression of the lesion two months after the treatment without functional sequelae.

The broad and differential diagnosis includes other infectious fungal, bacterial and malignant neoplasms such as squamous cell carcinoma. Absence of a more intense inflammatory component, granulomas and the detection of BAAR allow the differential diagnosis with other infectious diseases. A carcinoma is easily distinguished by distinct findings.

Despite the wide knowledge about the clinical features of the BU in endemic countries, in other areas this diagnosis can be delayed or erroneously performed. In this context of globalization and ease of travel of infected patients, the knowledge of clinical aspects and criteria for the early diagnosis are of paramount importance for the prevention of functional deficiencies resulting from this infection.

Conflict of interest: Authors declare that there is no conflict of interest between the authors of the article.

Financial conflict of interest: Authors declare that they did not receive any financial support in this study.

Address correspondence to: Raimundo Geronimo, Silva Junior Lapac laboratory, Anísio de Abreu 502 / South, Teresina - Brazil Phone: +558632219141, e-mail: gerjrpi@gmail.com

\section{REFERENCES}

1. Boleira M, Lupi O, Lehman L, et al. Buruli ulcer. An Bras Dermatol. 2010;85(3):281-98.

2. Jacobsen $\mathrm{KH}$, Padgett JJ. Risk factors for Mycobacterium ulcerans infection. Int J Infect Dis. 2010;14(8):e677-81.

3. McGann H, Stragier P, Portaels F, et al. Buruli ulcer in United Kingdom tourist returning from latin america. Emerg Infect Dis. 2009;15(11):1827-9.

4. Nakanaga K, Yotsu RR, Hoshino Y, et al. Buruli ulcer and mycolactone-producing mycobacteria. Jpn $\mathrm{J}$ Infect Dis. 2013;66(2):83-8.

5. Van der Werf TS, Stienstra $Y$, Johnson RC et al. Mycobacterium ulcerans disease. Bull World Health Organ. 2005;83(10):785-91.

6. Portaels F. Laboratory diagnosis of buruli ulcer: A manual for health-care providers. Geneva, Switzerland: World Health Organization; 2014. 